\title{
Multi-Layered Epigenetic Regulatory Mechanisms Mediate Epithelial to Mesenchymal Transition in Cancer
}

Tara Boulding, Fan Wu, Anjum Zafar and Sudha Rao*

Faculty of Education, Science, Technology and Maths, University of Canberra, Canberra, ACT, Australia

*Corresponding author: Sudha Rao, Faculty of Education, Science, Technology \& Maths, University of Canberra, Canberra, ACT, Australia, Tel: 612 6201 5111; Email: sudha.rao@canberra.edu.au

Received date: Dec 24, 2014; Accepted date: Dec 26, 2014; Published date: Jan 2, 2015

Copyright: () 2015 Boulding, et al. This is an open-access article distributed under the terms of the Creative Commons Attribution License, which permits unrestricted use, distribution, and reproduction in any medium, provided the original author and source are credited.

\begin{abstract}
Epithelial to Mesenchymal Transition (EMT) is a central feature of embryonic development and is also a critical early event in cancer progression and metastasis. Our understanding of the complexity of the chromatin platform and the epigenetic mechanisms that contribute to transcriptional control has expanded dramatically in recent years. These mechanisms include the presence/absence of histone modifications, which form epigenetic signatures that mark active or inactive genes. These signatures are dynamically added or removed by a wide variety of histonemodifying epigenetic enzymes, which more recently have been found to include chromatin-associated signalling kinases. Here, we discuss the multi-layered regulation of gene transcription during EMT in cancer. Given that epigenetics-based therapeutics are showing promise for the treatment of cancer, unravelling the detail of these epigenetic signatures during EMT is crucial to the development of novel therapeutic strategies that exploit these mechanisms.
\end{abstract}

Keywords: Epithelial to Mesenchymal Transition (EMT); Neoplastic epithelial cells; Epidermal Growth Factor (EGF)

\section{EMT is a key step in cancer progression and metastasis}

Epithelial to Mesenchymal Transition (EMT) is a process of dynamic and reversible phenotypic switching.EMT is essential for driving plasticity in embryonic development and, importantly, in cancer progression (Figure 1) [1-3]. During EMT, differentiated neoplastic epithelial cells lose cell-cell adhesion and apical-basal polarity while acquiring a mesenchymal phenotype; specifically, cells gain motility and migration capabilities, become resistant to apoptosis, and exhibit increased invasiveness [4-7]. Neoplastic cells have inherent flexibility to exist in multiple states ranging from a fully differentiated epithelial state to a fully dedifferentiated mesenchymal state $[4,8,9]$. This phenotypic spectrum of cellular plasticity is largely attributed to multiple rounds of EMT and its opposite process mesenchymal to epithelial transition (MET) [10].

Physiological activation of EMT can be triggered by paracrine and autocrine EMT-inducing growth factors that activate downstream intracellular signalling cascades $[4,11,12]$. It is thought that the absence of such signalling can cause MET; thus, continuous signalling is essential for maintaining the mesenchymal characteristics of cells undergoing EMT [12,13]. Numerous growth factors such as transforming growth factor-beta (TGF- $\beta$ ), fibroblast growth factor (FGF), epidermal growth factor (EGF), and hepatocyte growth factor (HGF) can induce EMT by triggering a number of different signalling pathways including TGF- $\beta$, Wnt, and Notch [11,14-18]. Combinatorial activation of these signalling pathways results in the activation of several EMT-inducing transcription factors (EMT-TFs) such as Snail, Slug, ZEB-1, ZEB-2, Twist, and members of the NF- $\kappa B$ family $[15,16,19-25]$. EMT-TFs have been shown to cooperate at key EMT gene promoters as part of complex regulatory networks that regulate gene transcription to drive EMT progression [26].

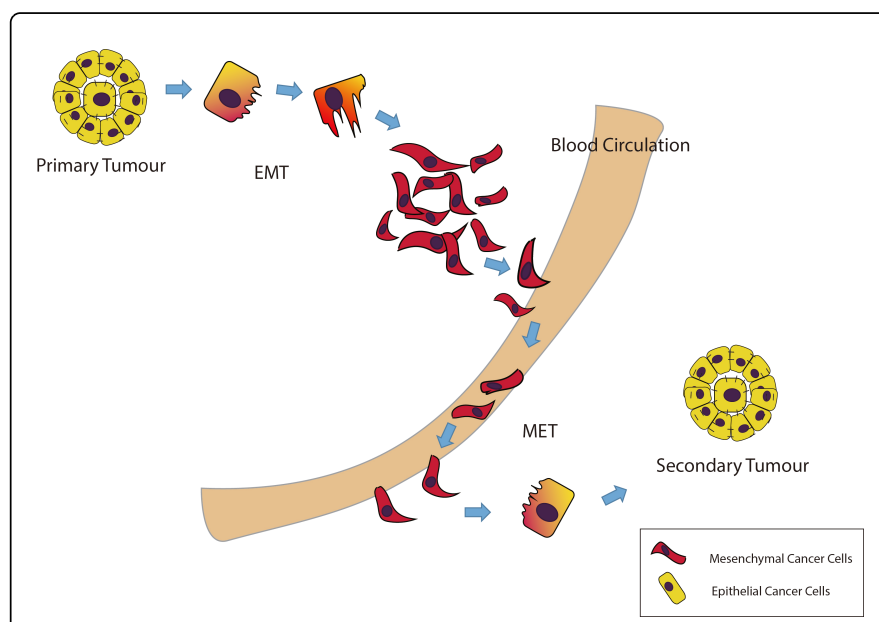

Figure 1: EMT is involved in cancer metastasis Neoplastic epithelial cells can undergo epithelial to Mesenchymal Transition (EMT) during early stages of metastasis. EMT enables migration and intravasation of tumour cells, allowing their passive transport to distal locations in the body. At secondary sites, extravasation followed by mesenchymal to epithelial transition (MET) generates new tumours.

Several studies have demonstrated the central and cooperative manner in which EMT-TFs regulate EMT. For example, Snail knockdown reduces cell migration and invasion and induces MET, while Snail over expression increases cell migration and invasion and induces EMT [27-29]. Similarly, Twist over expression upregulates mesenchymal markers, and cell migration, and induces EMT [30]. Slug is also an essential mediator of Twist-induced EMT, and Twist expression can induce Snail and hence initiate EMT [31,32]. 
Importantly, a large number of the genes controlled by EMT-TFs encode functional proteins such as the inducible mesenchymal markers vimentin, fibronectin, and $\mathrm{N}$-cadherin and repressible epithelial markers that include E-cadherin $[33,34]$. The expression of these markers is not mutually exclusive, since differentiated epithelial cells may undergo partial EMT and co-express both epithelial and mesenchymal markers (Figure 2). Perhaps the most studied change in EMT is the hallmark loss of E-cadherin expression. E-cadherin (encoded by $\mathrm{CDH1}$ ) is an adherens junction protein and a key repressor of cellular metastasis [35]. Loss of E-cadherin expression in in vitro culture systems and in vivo mouse models initiates EMT and enhances tumour metastasis [36,37]. The multifaceted epigeneticsbased regulation of $\mathrm{CDH} 1$ is discussed in detail below.

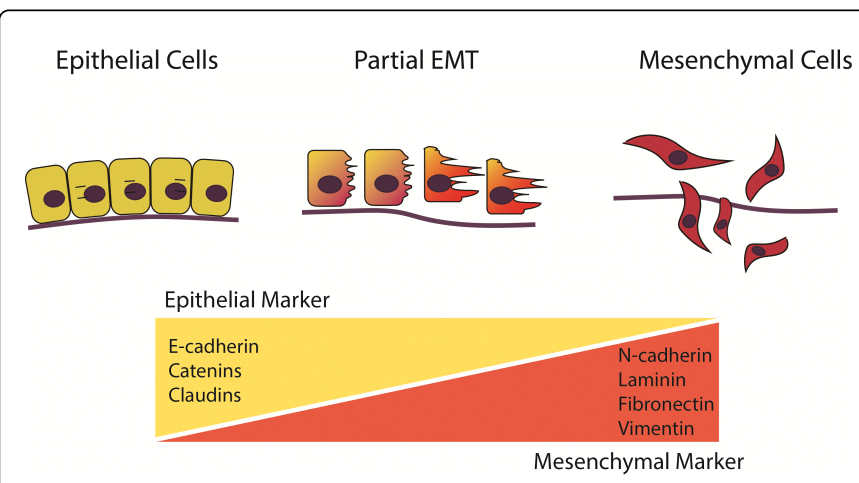

Figure 2: A distinct set of proteins mark epithelial, mesenchymal and partially transitioned cells. Epithelial to mesenchymal transition is a morphogenetic process where cells lose cell-cell contact and apical-basal polarity to acquire partial EMT status. Subsequently, cells gain more motility by restructuring epithelial actin architecture to achieve a full mesenchymal state. The expression of proteins dynamically changes during EMT and distinct markers define the phenotype of the cells. Cells express more E-cadherin, catenins and claudins in an epithelial state, and gradually lose the expression of these proteins while gaining more mesenchymal markers, including N-Cadherin, laminin, fibronectin and vimentin in amesenchymal state.

Recently, microRNAs (miRNAs) have been established as important regulators of EMT. miRNAs are a class of short non-coding RNA molecules involved in the RNA interference machinery. They selectively bind to target messenger RNAs (mRNA), mostly in the $3^{\prime}$ untranslated region, to post-transcriptionally regulate mRNA expression [38,39]. Many miRNAs have been implicated in EMT regulation including the miR-200 family (miR-200a, miR-200b, miR-200c, miR-141, and miR-429), miR-205, miR-34, and miR-21 [40-42]. These miRNAs have a close functional relationship with a number of EMT-TFs including ZEB-1, ZEB-2, Snail, and NF- $\kappa B$ $[40,41,43,44]$. The relationship between the miR-200 family and ZEB family members is particularly well established [40]. During TGF- $\beta$ induced EMT, ZEBs are activated and they repress the activity of miR-200 family members, which in turn represses ZEB activity and thus regulates EMT via a double-negative feedback loop $[45,46]$. Intriguingly, this miR-200/ZEB balance can consecutively switch cells between epithelial and mesenchymal states in both directions [47]. High miR-200/low ZEB expression is associated with the pure epithelial state, while low miR-200/high ZEB expression is associated with the pure mesenchymal state [48]. Intermediate miR-200/ZEB expression represents the hybridised, partial EMT phenotype [48].

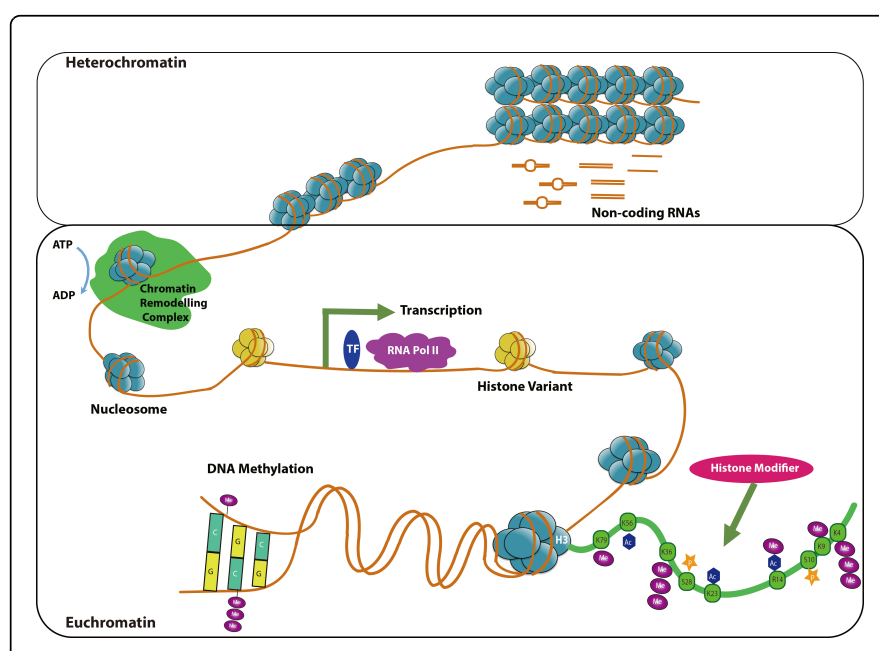

Figure 3: Model for the multi-layered transcriptional mechanisms that mediate induction of gene expression programs. In response to extracellular signaling cues, a distinct cohort of genes are induced in the mesenchymal state. At such gene loci, chromatin can be reconfigured to an accessible state via nucleosome repositioning/ eviction, histone variant exchange or DNA methylation and posttranscriptional modification of histones. Histone modifiers including histone acetyltransferases, histone methyltransferases, and histone kinases can modify the histone tails by mediating acetylation, methylation, and phosphorylation, respectively. Ultimately, this leads to the exposure of key transcription factor DNA recognition elements, the binding of the factors and the recruitment of the RNA polymerase II transcription machinery. Non-coding RNAs are capable of maintaining heterochromatin formation. ATP: adenosine triphosphate; ADP: adenosine diphosphate; Ac: acetylation; Me: methylation; P: phosphorylation; TF: transcription factor; R: arginine; K: lysine; $\mathrm{T}$ : threonine; $\mathrm{S}$ : serine.

\section{Epigenetic modifications control gene expression}

Eukaryotes utilise the chromatin landscape as an epigenetic template to regulate gene transcription. Dynamic changes in chromatin structure (chromatin remodelling) play a key role in regulating genome function [49-51]. Highly compacted chromatin structures are enriched in nucleosomes and are transcriptionally silent. In contrast: a net loss of nucleosomes from gene-specific regulatory regions increases chromatin accessibility: enables binding of transcriptional regulators: and initiates gene expression [52,53]. With respect to transcription: chromatin predominantly exists in two interchangeable states: transcriptionally silent heterochromatin or transcriptionally active euchromatin (Figure 3). Chromatin remodelling orchestrates a gene's transcriptional state via a number of mechanisms: (1) post-translational modifications of histone proteins; (2) DNA methylation; (3) the actions of ATP-dependent chromatinremodelling complexes; (4) exchange of canonical histones with one of the variant histones; and (5) the action of non-coding RNAs [54,55]. This review focuses on the multiple layers of epigenetic control that govern EMT regulation in cancer. 


\section{Epigenetic signatures are mediated by dynamic epigenetic enzymes}

Post-translational modifications (PTMs) of the amino tails of histones are thought to be particularly important modulators of gene expression: either by changing chromatin structure and/or by providing a 'histone code' that acts as a tag for the tethering of transcriptional regulators to the epigenetic template [56]. These histone tags have typically been ascribed to either gene activation or repression depending on their location. For example: the promoter regions of actively transcribed genes are commonly enriched in $\mathrm{H} 3 \mathrm{~K} 4$ acetylation and H3K4: H3K36: and H3K79 tri-methylation. In contrast: the promoter regions of repressed genes are commonly enriched in H3K9 and H3K27 tri-methylation [57-60]. However: it is becoming increasingly apparent that a single PTM does not dictate the transcriptional outcome. Instead: it has been suggested that chromatin needs to be considered a 'composite domain' in which modifications work simultaneously to regulate gene expression [61].

These dynamic and reversible PTMs are orchestrated by numerous histone-modifying enzymes that can write or erase the histone code peppered across gene loci. For example: histone acetylation is catalysed by histone acetyl transferases (HATs): which transfer an acetyl group to lysine residues on $\mathrm{H} 3$ and $\mathrm{H} 4$ [62,63]. Histone acetylation neutralises the basic charge of lysine: consequently destabilising higher order chromatin folding leading to transcription [64,65]. The opposing deacetylation is catalysed by histone deacetylases (HDACs): which remove acetyl groups and thus repress transcription [66]. Indeed: global loss of H4K19ac is a common hallmark in human cancers: indicating that HDACs are important in tumourigenesis [67]. Moreover: HDACs have been found to be over expressed in several different cancer types including breast: colorectal: gastric: prostate: and renal cancers [68-72]. HDACs have been shown to have an important regulatory role in EMT. For example: HDAC1 is required for TGF- $\beta$-induced EMT: while HDAC3 is required for hypoxiainduced EMT after interacting with WDR5 [73,74]. Increased HDAC expression is also associated with increased proliferation: differentiation: invasion: and metastasis $[69,75,76]$.

Compared to histone acetylation: histone methylation is a multifaceted modification since it can occur on arginine and lysine residues and can both activate and repress transcription [77]. Moreover: lysine residues may be mono-: di-: or tri-methylated: and arginine residues may be mono- or di-methylated. Methylation increases the hydrophobicity of histone side chains: increasing their affinity for transcriptional activators or repressors depending on the modified amino acid residue [78]. Methylation of H3K4: H3K36: or H3K79 recruits proteins responsible for activating transcription: whereas methylation of H3K9: H3K27: or H4K20 recruits transcriptional repressors that subsequently block transcription [57]. Until recently: methylation was thought to be a static modification; however: it is now known that demethylation is catalysed by lysinespecific demethylases (LSD1 and LSD2) and Jumanji C (JmjC) domain-containing proteins [57,79-81]. Both demethylate mono- and di-methylated lysine residues on histone 3 and can activate and repress transcription [79,82-85]. Several lysine methyl transferases interact with EMT-TFs to promote EMT. For example: MMSET directly regulates Twist expression by triggering $\mathrm{H} 3 \mathrm{~K} 36$ tri-methylation on the TWIST1 promoter: thus regulating EMT [86]. Set8 can physically interact with Twist to mono-methylate $\mathrm{H} 4 \mathrm{~K} 20$ on epithelial gene promoters: consequently initiating EMT and increasing the invasiveness of breast cancer cells [87]. Similarly: G9a catalyses H3K9 di-methylation on epithelial gene promoters: subsequently repressing their expression in a TGF- $\beta$-induced EMT model [88]. Intriguingly: global loss of $\mathrm{H} 4 \mathrm{~K} 20 \mathrm{me} 3$ is a hallmark of cancer: implicating demethylase activity in cancer regulation [67]. LSD1 expression is elevated in a number of different cancer types including bladder: lung: ovarian: and prostate cancers [82,89-92]. Moreover: LSD1 levels are significantly higher in early stage tumours indicating a possible role for LSD1 in the initiation of tumourigenesis [82]. A recent study demonstrated that LSD1 executes genome-wide epigenetic reprogramming of large organised heterochromatin K9-modifications (LOCKS) domains in a TGF- $\beta$-induced murine hepatocyte model of EMT; specifically: a genome-wide reduction in $\mathrm{H} 3 \mathrm{~K} 9 \mathrm{me} 2$ and an increase in H3K4me2 and H3K36me3 [93]. Moreover: a global increase in $\mathrm{H} 3 \mathrm{~K} 4 \mathrm{me} 3$ and a reduction in $\mathrm{H} 3 \mathrm{~K} 27 \mathrm{me} 3$ leads to transcription of EMT-related genes in a 'stepwise' prostate cancer EMT cell model [94]. Similarly: Twist-induced EMT stimulates a large-scale increase in $\mathrm{H} 3 \mathrm{~K} 4 \mathrm{me} 2$ and the bivalent $\mathrm{H} 3 \mathrm{~K} 4 \mathrm{me} 3 /$ H3K27me3 marks [95]. Collectively: these modifications appear to be essential for epithelial dedifferentiation.

In addition to these histone modifications: direct methylation of DNA plays a key role in transcriptional silencing. DNA methylation occurs at the 5' position of cytosine residues within CpG dinucleotides and is catalysed by DNA methyltransferase enzymes (DNMTs) $[54,96]$. The role of DNA methylation and DNMTs in cancer regulation is well characterised and has been reviewed elsewhere $[97,98]$. A recent study found an inverse correlation between promoter methylation and expression of the EMT-TFs Snail and Slug [99]. Intriguingly: one analysis showed that DNA methylation patterns remain largely unchanged in TGF- $\beta$-induced EMT [93]. However: another demonstrated increased hypomethylation of epithelial-specific methylation sites and increased hypermethylation of mesenchymalspecific methylation sites [100]. However: McDonald et al. treated cells with TGF- $\beta$ for 36 hours while Ruike et al. treated cells for five days: and the discrepancy between these results might indicate that TGF- $\beta$ treatment longer than 36 hours is required to mediate changes in DNA methylation.

\section{Signalling kinases have emerged as a novel class of epigenetic enzymes in EMT}

It is widely understood that protein kinases are key participants of the signal transduction cascades that relay information from the cell surface to the nucleus to modulate gene expression programs [101-103]. The co-ordinated action and activation of these proteins provides the exquisite control necessary for the initiation of specific transcription programs. Traditionally: the action of signaling kinases was thought to predominantly occur in the cytoplasm. However: pioneering studies in yeast have shown that signal transduction kinases translocate to the nucleus and stably associate with the promoter and transcribed regions of genes to regulate expression $[104,105]$. These chromatin-tethered kinases have been shown to have both a structural role as part of transcription complexes and an enzymatic role by phosphorylating their target proteins [105-108].

There is growing evidence in higher eukaryotes that signal transduction kinases can have distinct functions in the cytoplasm and nucleus. For example: two upstream kinases in the NF- $\kappa B$ pathway: IKK1 and NIK: shuttle between the cytoplasm and nucleus in resting cells to facilitate basal NF- $\kappa B$ transcriptional activity [109]. IKK- $\alpha$ was shown to have an alternative role as a histone kinase that directly phosphorylates $\mathrm{H} 3 \mathrm{~S} 10$ at NF- $\mathrm{kB}-$ responsive gene promoters [110,111]. 
Page 4 of 9

The p38 Mitogen Activated Protein Kinase (MAPK) is another signalling kinase that is recruited to the chromatin of muscle-specific loci: where it targets the SWI-SNF chromatin remodelling complex [112]. These findings illustrate the more general role of signalling kinases as regulators of gene transcription in both higher and lower eukaryotic cells via two distinct mechanisms: (1) cytoplasmic signalling to the nucleus and (2) direct association with chromatinbound transcription complexes at activated target genes in the nucleus. For example: the novel PKC family member: PKC- $\theta$ : functions as an epigenetic enzyme and directly regulates key EMT genes in breast cancer [25]. In addition: the conventional PKC isoform: PKC- $\beta$ : also functions as an epigenetic enzyme by directly tethering to the epigenetic template and phosphorylating histone H3T6 residues and blocking demethylation in prostate cancer [113].

The NF- $\kappa B$ family member $\mathrm{p} 65$ and IKK- $\beta$ have been shown to play a role in TNF- $\alpha$-induced expression of Twist and subsequent initiation of EMT [114]. p38 MAPK also regulates TGF- $\beta$-induced EMT changes in pulmonary epithelial cells [115]. Similarly: PKC- $\alpha$ has been shown to be a central regulator of cells that have undergone an EMT program [116]. However: it remains to be determined whether these enzymes mediate their actions through epigenetic mechanisms. Crosstalk between signalling kinases and the epigenetic platform in the context of EMT is: therefore: an emerging and key research area.

\section{E-cadherin: a paradigm for epigenetic regulation of EMT}

Epigenetic control is highly complex and involves co-ordinated: multi-layered regulation. $\mathrm{CDH} 1$ is a model gene for analysing epigenetic regulation since it is necessary for maintaining epithelial structure and preventing EMT [35] (Figure 4). When CDH1 transcription is occurring in epithelial cells: the CDH1 promoter is enriched with the H3K4me2 euchromatin mark and the histone variant $\mathrm{H} 2 \mathrm{~A}$. $\mathrm{Z}$ [117,118]. In contrast: $\mathrm{CDH} 1$ repression is accompanied by the H3K9me2: H4K20me1: and H3K27me3 heterochromatin marks and hypermethylation and eviction of H2A.Z on the CDH1promoter $[87,88,117,119,120]$.

After activation of EMT-related signalling pathways: the EMT-TFs Snail: Zeb-1: and Twist are activated [19]. Snail binds to the E-box region of the $\mathrm{CDH} 1$ promoter and recruits several chromatinremodelling complexes including the $\mathrm{Mi}-2 /$ nucleosome remodelling and deacetylase $(\mathrm{NuRD})$ repressive complex and polycomb repressive complex 2 (PRC2). The NuRD complex contains a number of proteins including HDAC1: HDAC2: mSin3A: and LSD1 [121-123]. It catalyses the removal of di-methylated $\mathrm{H} 3 \mathrm{~K} 4$ and deacetylation of $\mathrm{H} 3$ and $\mathrm{H} 4$ $[118,121]$. PRC2 contains the PcG proteins EZH2 and SUZ12: which function together to catalyse H3K27 tri-methylation [13,119]. Mi-2/ $\mathrm{NuRD}$ and PRC2 recruitment leads to E-cadherin downregulation. Moreover: Snail induces ZEB-1 expression: which: in a similar manner: binds to the E-box region of the $\mathrm{CDH} 1$ promoter and recruits chromatin-remodelling proteins such as BRG1: which consequently suppresses E-cadherin expression [124,125]. Likewise: Twist represses CDH1 transcription by recruiting other partners such as BMI1 and SET8. In complex: BMI1 recruits PRC2: catalysing H3K27 trimethylation: while SET8 catalyses H4K20 mono-methylation on the CDH1 promoter $[87,126]$. Twist can also recruit the Mi-2NuRD complex to the CDH1 promoter to repress transcription [127].

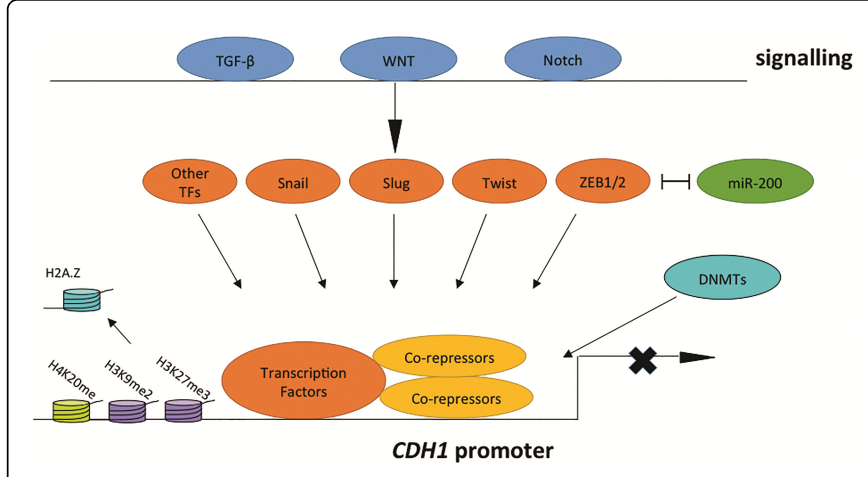

Figure 4: E-cadherin expression is regulated by layers of epigenetic control in EMT. The regulation of the $\mathrm{CDH} 1$ gene involves multiple layers of epigenetic regulation. Extracellular signaling pathways including TGF- $\beta$ : Wnt: and Notch activate EMTinducing transcription factors (EMT-TFs) such as Snail: Slug: Twist and ZEB-1/2. The EMT-TFs recruit various co-repressors which cooperatively repress $\mathrm{CDH} 1$ transcription. The $\mathrm{CDH} 1$ promoter is flanked by repressive histone marks like $\mathrm{H} 3 \mathrm{~K} 9 \mathrm{me} 2 \mathrm{H} 3 \mathrm{~K} 27 \mathrm{me} 3$ and H4K20me1. DNMTs can be recruited to the CDH1 promoter to repress gene transcription. $\mathrm{CDH} 1$ repression is also accompanied by the loss of histone variant: H2A.Z. The activity of some EMTTFs such as ZEB- $1 / 2$ is regulated through a negative feedback loop involving members of the miR-200 family.

As well as histone modifications: genome-wide profiling has identified hypermethylation of the $\mathrm{CDH} 1$ promoter as a transcriptional repressor [120,128]. Intriguingly: cell division cycle 6 (Cdc6) protein binding on the $\mathrm{CDH} 1$ promoter evicts H2A.Z: leading to E-cadherin repression [117].

\section{Epigenetic therapy is emerging as an effective treatment for cancer}

Global changes in the epigenetic landscape are a hallmark of cancer. The reversible nature of epigenetic aberrations has led to the emergence of the promising field of epigenetic therapy. Inhibitors of histone-modifying enzymes have recently shown promise as cancer therapeutics: with several 'epi-drugs' approved for clinical use [129]. Thus: determining the molecular mechanisms underpinning EMT and: in particular: distinct mesenchymal phenotypes such as cancer stem cells (CSCs) will be critical for the development of novel therapeutic strategies that target EMT in cancers.

The main epigenetic drugs being used in cancer clinical trials are HDAC inhibitors (HDACIs). HDACIs display anti-cancer activity by inhibiting angiogenesis and causing cell-cycle arrest [130-132]. Additionally: they are anti-proliferative and have the ability to selectively target cancer cells [133]. Importantly: clinical studies have shown that HDACIs are generally well tolerated and thus may have a safety profile suitable for widespread clinical use [134]. The first epigenetic enzyme to be approved by the Food and Drug Administration (FDA) was the HDACIvorinostat (suberanilohydroxamic acid; SAHA): after two successful phase II clinical trials in patients with cutaneous T-cell lymphoma $[135,136]$. Recent clinical trials are now using vorinostat in combination regimens to enhance the clinical efficacy $[137,138]$. Other HDACIs such as panobinostat and belinostat have been tested as monotherapies 
Page 5 of 9

and as part of combination therapies in clinical trials with promising results [139-141].

Several epigenetic inhibitors have been shown to be effective repressors of EMT: predominantly by upregulating E-cadherin. Treatment with the DNMT inhibitor 5-aza-2'-deoxycytidine (5-AzadC) blocks $\mathrm{CDH} 1$ hypermethylation: restores E-cadherin expression: and initiates morphological MET in numerous cancer types [142,143]. 5-Aza-dC treatment also increases E-cadherin expression and in vivo metastases of breast cancer cells in a SCID mouse xenograft model [144]. Similarly: treatment with the HDACI butyrate stimulates Ecadherin upregulation in colon and hepatocellular cancer cells: while the HDACIs vorinostat and TSA also capable of stimulating Ecadherin expression in endometrial carcinoma cells [145-147].A recent report has shown that the HDACI entinostat causes MET by reversing E-cadherin repressionin breast cancer cells [148]. However: it is important to note that HDACIs have been shown to induce EMT in prostate adenocarcinoma: endometrial adenocarcinoma: and head and neck squamous cell carcinoma cells [149-151]. These findings highlight the need to understand the molecular mechanisms underpinning their targeted inhibition. Additionally: a recent study demonstrated the benefits of using epigenetic inhibitors in combination with chemo immunotherapy; specifically: the DNMT inhibitor decitabine was used to enhance NY-ESO-1 vaccine-induced immunity in patients with relapsed epithelial ovarian cancer [152]. Intriguingly: a receptor tyrosine kinase small-molecule inhibitor: sorafenib: inhibits TGF- $\beta$-induced EMT by epigenetically regulating EMT-associated genes. Specifically: sorafenib reverses the histones modified during TGF- $\beta$-induced EMT [153].

It is now well known that EMT generates a subpopulation of CSCs that are capable of extensive proliferation and differentiation [154]. Thus: novel EMT-based epigenetic therapies should focus on targeting this important subpopulation of cells that gives rise to metastases and recurrent disease. As novel classes of chromatin-associated enzymes are discovered as key regulators of CSCs and EMT: increasing numbers of small-molecule inhibitors with therapeutic potential are becoming available: including LSD1 and PKC inhibitors. LSD1 inhibitors selectively inhibit proliferation of pluripotent teratocarcinoma: embryonic carcinoma: seminoma: and embryonic stem cells while sparing non-pluripotent cells [155]. A number of PKC inhibitors have emerged as novel drugs with the potential to be used as therapeutic agents against EMT and CSCs.Gö6976: a PKC- $\alpha$ inhibitor: abrogates upregulation of Snail and downregulation of claudins after hypoxia-induced EMT in pancreatic cancer cells [156]. Some smallmolecule PKC- $\delta$ inhibitors inhibit proliferation of the CSC niche in breast: pancreatic: and prostate cancer cell lines and in a breast cancer mouse xenograft model [157]. Several other PKC- $\alpha$ inhibitors: including Ro-31-8220 and bisindolylmaleimide I: reduce CSCenriched subpopulations and tumour initiation enriched by the CSC subset [116]. Similarly: aurothiomalate: a novel PKC-ı inhibitor: selectively targets the stem cell niche of bronchioalveolar cells in an anti-proliferative manner: indicating its potential in targeting CSCs [158]. Our recent findings that show PKC- $\theta$ directly tethers to chromatin and regulates inducible gene expression in PMA-induced EMT and CSCs: which is abrogated after treatment with a PKC- $\theta$ specific inhibitor [25]. PKC- $\theta$ is another novel epigenetics-based therapeutic target that needs to be explored in the clinic [25].

\section{Future Directions}

Recent data have exemplified the key role of epigenetic regulatory mechanisms in EMT: a critical step in tumour metastasis and recurrent aggressive disease. Epigenetics-based therapeutics hold great promise in the field of cancer biology: but it will be essential to uncover the multi-layered epigenetic regulatory mechanisms that occur during EMT to expedite this therapeutic approach (Figure 3). Given that cancer is a highly heterogeneous disease: understanding the molecular wiring in specific cancer cell subsets such as CSCs: especially in poor prognosis cancers with limited therapeutic options (such as pancreatic and ovarian cancer): will also be necessary. This strategy will undoubtedly aid the development of new therapeutic strategies in many cancers in which current therapeutic options are limited.

\section{References}

1. Hay ED (1995) An overview of epithelio-mesenchymal transformation. Acta Anat (Basel) 154: 8-20.

2. Thiery JP, Sleeman JP (2006) Complex networks orchestrate epithelialmesenchymal transitions. Nat Rev Mol Cell Biol 7: 131-142.

3. Yu M, Bardia A, Wittner BS, Stott SL, Smas ME, et al. (2013) Circulating breast tumor cells exhibit dynamic changes in epithelial and mesenchymal composition. Science 339: 580-584.

4. Boyer B, Vallés AM, Edme N (2000) Induction and regulation of epithelial-mesenchymal transitions. Biochem Pharmacol 60: 1091-1099.

5. Radisky DC (2005) Epithelial-mesenchymal transition. J Cell Sci 118: 4325-4326.

6. Larue L, Bellacosa A (2005) Epithelial-mesenchymal transition in development and cancer: role of phosphatidylinositol 3' kinase/AKT pathways. Oncogene 24: 7443-7454.

7. Kalluri R, Weinberg RA (2009) The basics of epithelial-mesenchymal transition. J Clin Invest 119: 1420-1428.

8. Huang RY, Guilford P, Thiery JP (2012) Early events in cell adhesion and polarity during epithelial-mesenchymal transition. J Cell Sci 125: 4417-4422.

9. Tam WL, Weinberg RA (2013) The epigenetics of epithelialmesenchymal plasticity in cancer. Nat Med 19: 1438-1449.

10. Thiery JP, Acloque H, Huang RY, Nieto MA (2009) Epithelialmesenchymal transitions in development and disease. Cell 139: 871-890.

11. Jechlinger M, Sommer A, Moriggl R, Seither P, Kraut N, et al. (2006) Autocrine PDGFR signaling promotes mammary cancer metastasis. J Clin Invest 116: 1561-1570.

12. Scheel C, Eaton EN, Li SH, Chaffer CL, Reinhardt F, et al. (2011) Paracrine and autocrine signals induce and maintain mesenchymal and stem cell states in the breast. Cell 145: 926-940.

13. Herranz N, Pasini D, Díaz VM, Francí C, Gutierrez A, et al. (2008) Polycomb complex 2 is required for E-cadherin repression by the Snaill transcription factor. Mol Cell Biol 28: 4772-4781.

14. Strutz F, Zeisberg M, Ziyadeh FN, Yang CQ, Kalluri R, et al. (2002) Role of basic fibroblast growth factor-2 in epithelial-mesenchymal transformation. Kidney Int 61: 1714-1728.

15. Lo HW, Hsu SC, Xia W, Cao X, Shih JY, et al. (2007) Epidermal growth factor receptor cooperates with signal transducer and activator of transcription 3 to induce epithelial-mesenchymal transition in cancer cells via up-regulation of TWIST gene expression. Cancer Res 67: 9066-9076.

16. Savagner P, Yamada KM, Thiery JP (1997) The zinc-finger protein slug causes desmosome dissociation, an initial and necessary step for growth factor-induced epithelial-mesenchymal transition. J Cell Biol 137: 1403-1419.

17. Jiang YG, Luo Y, He DL, Li X, Zhang LL, et al. (2007) Role of Wnt/betacatenin signaling pathway in epithelial-mesenchymal transition of 
human prostate cancer induced by hypoxia-inducible factor-1alpha. Int $J$ Urol 14: 1034-1039.

18. Timmerman LA, Grego-Bessa J, Raya A, Bertrán E, Pérez-Pomares JM, et al. (2004) Notch promotes epithelial-mesenchymal transition during cardiac development and oncogenic transformation. Genes Dev 18: 99-115.

19. Zheng H, Kang Y (2014) Multilayer control of the EMT master regulators. Oncogene 33: 1755-1763.

20. Peinado H, Quintanilla M, Cano A (2003) Transforming growth factor beta-1 induces snail transcription factor in epithelial cell lines: mechanisms for epithelial mesenchymal transitions. J Biol Chem 278: 21113-21123.

21. Sahlgren C, Gustafsson MV, Jin S, Poellinger L, Lendahl U (2008) Notch signaling mediates hypoxia-induced tumor cell migration and invasion.Proc Natl Acad Sci U S A 105: 6392-6397.

22. Romano LA, Runyan RB (2000) Slug is an essential target of TGFbeta2 signaling in the developing chicken heart. Dev Biol 223: 91-102.

23. Comijn J, Berx G, Vermassen P, Verschueren K, van Grunsven L, et al. (2001) The two-handed E box binding zinc finger protein SIP1 downregulates E-cadherin and induces invasion. Mol Cell 7: 1267-1278.

24. Huber MA, Azoitei N, Baumann B, Grünert S, Sommer A, et al. (2004) NF-kappaB is essential for epithelial-mesenchymal transition and metastasis in a model of breast cancer progression. J Clin Invest 114: 569-581.

25. Zafar A, Wu F, Hardy K, Li J, Tu WJ, et al. (2014) Chromatinized protein kinase C-Î, directly regulates inducible genes in epithelial to mesenchymal transition and breast cancer stem cells. Mol Cell Biol 34: 2961-2980.

26. Peinado H, Olmeda D, Cano A (2007) Snail, Zeb and bHLH factors in tumour progression: an alliance against the epithelial phenotype? Nat Rev Cancer 7: 415-428.

27. Cano A, Pérez-Moreno MA, Rodrigo I, Locascio A, Blanco MJ, et al. (2000) The transcription factor snail controls epithelial-mesenchymal transitions by repressing E-cadherin expression. Nat Cell Biol 2: 76-83.

28. Zhou W, Lv R, Qi W, Wu D, Xu Y, et al. (2014) Snail contributes to the maintenance of stem cell-like phenotype cells in human pancreatic cancer. PLoS One 9: e87409.

29. Wang H, Zhang G, Zhang H, Zhang F, Zhou B, et al. (2014) Acquisition of epithelial-mesenchymal transition phenotype and cancer stem cell-like properties in cisplatin-resistant lung cancer cells through AKT/betacatenin/Snail signaling pathway. Eur J Pharmacol 723: 156-166.

30. Yang J, Mani SA, Donaher JL, Ramaswamy S, Itzykson RA, et al. (2004) Twist, a master regulator of morphogenesis, plays an essential role in tumor metastasis. Cell 117: 927-939.

31. Casas E, Kim J, Bendesky A, Ohno-Machado L, Wolfe CJ, et al. (2011) Snail2 is an essential mediator of Twist1-induced epithelial mesenchymal transition and metastasis. Cancer Res 71: 245-254.

32. Smit MA, Geiger TR, Song JY, Gitelman I, Peeper DS (2009) A TwistSnail axis critical for TrkB-induced epithelial-mesenchymal transitionlike transformation, anoikis resistance, and metastasis. Mol Cell Biol 29: 3722-3737.

33. De Craene B, Gilbert B, Stove C, Bruyneel E, van Roy F, et al. (2005) The transcription factor snail induces tumor cell invasion through modulation of the epithelial cell differentiation program. Cancer Res 65: 6237-6244.

34. Vandewalle C, Comijn J, De Craene B, Vermassen P, Bruyneel E, et al. (2005) SIP1/ZEB2 induces EMT by repressing genes of different epithelial cell-cell junctions. Nucleic Acids Res 33: 6566-6578.

35. Birchmeier W, Behrens J (1994) Cadherin expression in carcinomas: role in the formation of cell junctions and the prevention of invasiveness. Biochim Biophys Acta 1198: 11-26.

36. Derksen PW, Liu X, Saridin F, van der Gulden H, Zevenhoven J, et al. (2006) Somatic inactivation of E-cadherin and p53 in mice leads to metastatic lobular mammary carcinoma through induction of anoikis resistance and angiogenesis. Cancer Cell 10: 437-449.
37. Onder TT, Gupta PB, Mani SA, Yang J, Lander ES, et al. (2008) Loss of Ecadherin promotes metastasis via multiple downstream transcriptional pathways. Cancer Res 68: 3645-3654.

38. Bartel DP (2004) MicroRNAs: genomics, biogenesis, mechanism, and function. Cell 116: 281-297.

39. Sato F, Tsuchiya S, Meltzer SJ, Shimizu K (2011) MicroRNAs and epigenetics. FEBS J 278: 1598-1609.

40. Gregory PA, Bert AG, Paterson EL, Barry SC, Tsykin A, et al. (2008) The miR-200 family and miR-205 regulate epithelial to mesenchymal transition by targeting ZEB1 and SIP1. Nat Cell Biol 10: 593-601.

41. Siemens H, Jackstadt R, Hünten S, Kaller M, Menssen A, et al. (2011) miR-34 and SNAIL form a double-negative feedback loop to regulate epithelial-mesenchymal transitions. Cell Cycle 10: 4256-4271.

42. Zavadil J, Narasimhan M, Blumenberg M, Schneider RJ (2007) Transforming growth factor-beta and microRNA:mRNA regulatory networks in epithelial plasticity. Cells Tissues Organs 185: 157-161.

43. Moes M, Le Béchec A, Crespo I, Laurini C, Halavatyi A, et al. (2012) A novel network integrating a miRNA-203/SNAI1 feedback loop which regulates epithelial to mesenchymal transition. PLoS One 7: e35440.

44. Li QQ, Chen ZQ, Cao XX, Xu JD, Xu JW, et al. (2011) Involvement of NF-Î́B/miR-448 regulatory feedback loop in chemotherapy-induced epithelial-mesenchymal transition of breast cancer cells. Cell Death Differ 18: 16-25.

45. Bracken CP, Gregory PA, Kolesnikoff N, Bert AG, Wang J, et al. (2008) A double-negative feedback loop between ZEB1-SIP1 and the microRNA-200 family regulates epithelial-mesenchymal transition. Cancer Res 68: 7846-7854.

46. Park SM, Gaur AB, Lengyel E, Peter ME (2008) The miR-200 family determines the epithelial phenotype of cancer cells by targeting the Ecadherin repressors ZEB1 and ZEB2. Genes Dev 22: 894-907.

47. Gregory PA, Bracken CP, Smith E, Bert AG, Wright JA, et al. (2011) An autocrine TGF-beta/ZEB/miR-200 signaling network regulates establishment and maintenance of epithelial-mesenchymal transition. Mol Biol Cell 22: 1686-1698.

48. Lu M, Jolly MK, Levine H, Onuchic JN, Ben-Jacob E (2013) MicroRNAbased regulation of epithelial-hybrid-mesenchymal fate determination. Proc Natl Acad Sci U S A 110: 18144-18149.

49. Hager GL, McNally JG, Misteli T (2009) Transcription dynamics. Mol Cell 35: 741-753.

50. Rao S, Procko E, Shannon MF (2001) Chromatin remodeling, measured by a novel real-time polymerase chain reaction assay, across the proximal promoter region of the IL-2 gene. J Immunol 167: 4494-4503.

51. Aoyagi S, Narlikar G, Zheng C, Sif S, Kingston RE, et al. (2002) Nucleosome remodeling by the human SWI/SNF complex requires transient global disruption of histone-DNA interactions. Mol Cell Biol 22: 3653-3662.

52. Bell O, Tiwari VK, Thomä NH, Schübeler D (2011) Determinants and dynamics of genome accessibility. Nat Rev Genet 12: 554-564.

53. Li B, Carey M, Workman JL (2007) The role of chromatin during transcription. Cell 128: 707-719.

54. Portela A, Esteller M (2010) Epigenetic modifications and human disease. Nat Biotechnol 28: 1057-1068.

55. Tollervey JR, Lunyak VV (2012) Epigenetics: judge, jury and executioner of stem cell fate. Epigenetics 7: 823-840.

56. Strahl BD, Allis CD (2000) The language of covalent histone modifications. Nature 403: 41-45.

57. Kouzarides $\mathrm{T}$ (2007) Chromatin modifications and their function. Cell 128: 693-705.

58. Guillemette B, Drogaris P, Lin HH, Armstrong H, Hiragami-Hamada K, et al. (2011) H3 lysine 4 is acetylated at active gene promoters and is regulated by $\mathrm{H} 3$ lysine 4 methylation. PLoS Genet 7: e1001354.

59. Vakoc CR, Sachdeva MM, Wang H, Blobel GA (2006) Profile of histone lysine methylation across transcribed mammalian chromatin.Mol Cell Biol 26: 9185-9195. 
60. Wong CM, Wong CC, Ng YL, Au SL, Ko FC, et al. (2011) Transcriptional repressive $\mathrm{H} 3 \mathrm{~K} 9$ and $\mathrm{H} 3 \mathrm{~K} 27$ methylations contribute to DNMT1mediated DNA methylation recovery. PLoS One 6: e16702.

61. Margueron R, Reinberg D (2010) Chromatin structure and the inheritance of epigenetic information. Nat Rev Genet 11: 285-296.

62. Chen H, Tini M, Evans RM (2001) HATs on and beyond chromatin. Curr Opin Cell Biol 13: 218-224.

63. Gräff J, Tsai LH (2013) Histone acetylation: molecular mnemonics on the chromatin. Nat Rev Neurosci 14: 97-111.

64. Davie JR (1997) Nuclear matrix, dynamic histone acetylation and transcriptionally active chromatin. Mol Biol Rep 24: 197-207.

65. Tse C, Sera T, Wolffe AP, Hansen JC (1998) Disruption of higher-order folding by core histone acetylation dramatically enhances transcription of nucleosomal arrays by RNA polymerase III. Mol Cell Biol 18: 4629-4638.

66. Doetzlhofer A, Rotheneder H, Lagger G, Koranda M, Kurtev V, et al. (1999) Histone deacetylase 1 can repress transcription by binding to Sp1. Mol Cell Biol 19: 5504-5511.

67. Fraga MF, Ballestar E, Villar-Garea A, Boix-Chornet M, Espada J, et al. (2005) Loss of acetylation at Lys 16 and trimethylation at Lys20 of histone H4 is a common hallmark of human cancer. Nat Genet 37: 391-400.

68. Zhang Z, Yamashita H, Toyama T, Sugiura H, Ando Y, et al. (2005) Quantitation of HDAC1 mRNA expression in invasive carcinoma of the breast*. Breast Cancer Res Treat 94: 11-16.

69. Weichert W, Röske A, Niesporek S, Noske A, Buckendahl AC, et al. (2008) Class I histone deacetylase expression has independent prognostic impact in human colorectal cancer: specific role of class I histone deacetylases in vitro and in vivo. Clin Cancer Res 14: 1669-1677.

70. Choi JH, Kwon HJ, Yoon BI, Kim JH, Han SU, et al. (2001) Expression profile of histone deacetylase 1 in gastric cancer tissues. Jpn J Cancer Res 92: 1300-1304.

71. Halkidou K, Gaughan L, Cook S, Leung HY, Neal DE, et al. (2004) Upregulation and nuclear recruitment of HDAC1 in hormone refractory prostate cancer. Prostate 59: 177-189.

72. Fritzsche FR, Weichert W, Roske A, Gekeler V, Beckers T, et al. (2008) Class I histone deacetylases 1,2 and 3 are highly expressed in renal cell cancer. BMC Cancer 8: 381.

73. Lei W, Zhang K, Pan X, Hu Y, Wang D, et al. (2010) Histone deacetylase 1 is required for transforming growth factor-betal-induced epithelialmesenchymal transition. Int J Biochem Cell Biol 42: 1489-1497.

74. Wu MZ, Tsai YP, Yang MH, Huang CH, Chang SY, et al. (2011) Interplay between HDAC3 and WDR5 Is Essential for Hypoxia-Induced Epithelial-Mesenchymal Transition. Molecular Cell 43: 811-822.

75. Park SY, Jun JA, Jeong KJ, Heo HJ, Sohn JS, et al. (2011) Histone deacetylases 1, 6 and 8 are critical for invasion in breast cancer. Oncol Rep 25: 1677-1681.

76. Yasui W, Oue N, Ono S, Mitani Y, Ito R, et al. (2003) Histone acetylation and gastrointestinal carcinogenesis.Ann N Y Acad Sci 983: 220-231.

77. Zhang Y, Reinberg D (2001) Transcription regulation by histone methylation: interplay between different covalent modifications of the core histone tails. Genes Dev 15: 2343-2360.

78. Teperino R, Schoonjans K, Auwerx J (2010) Histone methyl transferases and demethylases; can they link metabolism and transcription? Cell Metab 12: 321-327.

79. Shi Y, Lan F, Matson C, Mulligan P, Whetstine JR, et al. (2004) Histone demethylation mediated by the nuclear amine oxidase homolog LSD1. Cell 119: 941-953.

80. Forneris F, Binda C, Vanoni MA, Battaglioli E, Mattevi A (2005) Human histone demethylase LSD1 reads the histone code. J Biol Chem 280: 41360-41365.

81. Forneris F, Binda C, Battaglioli E, Mattevi A (2008) LSD1: oxidative chemistry for multifaceted functions in chromatin regulation. Trends Biochem Sci 33: 181-189.

82. Hayami S, Kelly JD, Cho HS, Yoshimatsu M, Unoki M, et al. (2011) Overexpression of LSD1 contributes to human carcinogenesis through chromatin regulation in various cancers. Int J Cancer 128: 574-586.
83. Metzger E, Wissmann M, Yin N, Muller JM, Schneider R, et al. (2005) LSD1 demethylates repressive histone marks to promote androgenreceptor-dependent transcription. Nature 437: 436-439.

84. Yamane K, Toumazou C, Tsukada Y, Erdjument-Bromage H, Tempst P, et al. (2006) JHDM2A, a JmjC-containing H3K9 demethylase, facilitates transcription activation by androgen receptor. Cell 125: 483-495.

85. Tanaka Y, Okamoto K, Teye K, Umata T, Yamagiwa N, et al. (2010) JmjC enzyme KDM2A is a regulator of rRNA transcription in response to starvation. EMBO J 29: 1510-1522.

86. Ezponda T, Popovic R, Shah MY, Martinez-Garcia E, Zheng Y, et al. (2013) The histone methyltransferase MMSET/WHSC1 activates TWIST1 to promote an epithelial-mesenchymal transition and invasive properties of prostate cancer. Oncogene 32: 2882-2890.

87. Yang F, Sun L, Li Q, Han X, Lei L, et al. (2012) SET8 promotes epithelialmesenchymal transition and confers TWIST dual transcriptional activities. ЕMBO J 31: 110-123.

88. Dong C, Wu Y, Yao J, Wang Y, Yu Y, et al. (2012) G9a interacts with Snail and is critical for Snail-mediated E-cadherin repression in human breast cancer. J Clin Invest 122: 1469-1486.

89. Kauffman EC, Robinson BD, Downes MJ, Powell LG, Lee MM, et al. (2011) Role of androgen receptor and associated lysine-demethylase coregulators, LSD1 and JMJD2A, in localized and advanced human bladder cancer. Mol Carcinog 50: 931-944.

90. Kashyap V, Ahmad S, Nilsson EM, Helczynski L, Kenna S, et al. (2013) The lysine specific demethylase-1 (LSD1/KDM1A) regulates VEGF-A expression in prostate cancer. Mol Oncol 7: 555-566.

91. Lv T, Yuan D, Miao X, Lv Y, Zhan P, et al. (2012) Over-expression of LSD1 promotes proliferation, migration and invasion in non-small cell lung cancer. PLoS One 7: e35065.

92. Ding D, Liu X, Guo SW (2014) Overexpression of lysine-specific demethylase 1 in ovarian endometriomas and its inhibition reduces cellular proliferation, cell cycle progression, and invasiveness. Fertil Steril 101: 740-749.

93. McDonald OG, Wu H, Timp W, Doi A, Feinberg AP (2011) Genomescale epigenetic reprogramming during epithelial-to-mesenchymal transition. Nat Struct Mol Biol 18: 867-874.

94. Ke XS, Qu Y, Cheng Y, Li WC, Rotter V, et al. (2010) Global profiling of histone and DNA methylation reveals epigenetic-based regulation of gene expression during epithelial to mesenchymal transition in prostate cells. BMC Genomics 11: 669.

95. Malouf GG, Taube JH, Lu Y, Roysarkar T, Panjarian S, et al. (2013) Architecture of epigenetic reprogramming following Twist1-mediated epithelial-mesenchymal transition. Genome Biol 14: R144.

96. Chen T, Li E (2004) Structure and function of eukaryotic DNA methyltransferases. Curr Top Dev Biol 60: 55-89.

97. Kulis M, Esteller M (2010) DNA methylation and cancer. Adv Genet 70: 27-56.

98. McCabe MT, Brandes JC, Vertino PM (2009) Cancer DNA methylation: molecular mechanisms and clinical implications. Clin Cancer Res 15: 3927-3937.

99. Chen Y, Wang K, Qian CN, Leach R (2013) DNA methylation is associated with transcription of Snail and Slug genes. Biochem Biophys Res Commun 430: 1083-1090.

100. Ruike Y, Imanaka Y, Sato F, Shimizu K, Tsujimoto G (2010) Genomewide analysis of aberrant methylation in human breast cancer cells using methyl-DNA immunoprecipitation combined with high-throughput sequencing. BMC Genomics 11: 137.

101. Sutcliffe EL, Rao S (2011) Duplicity of protein kinase C-Î, : Novel insights into human T-cell biology. Transcription 2: 189-192.

102. Thomson S, Clayton AL, Hazzalin CA, Rose S, Barratt MJ, et al. (1999) The nucleosomal response associated with immediate-early gene induction is mediated via alternative MAP kinase cascades: MSK1 as a potential histone H3/HMG-14 kinase. EMBO J 18: 4779-4793. 
103. De Nadal E, Zapater M, Alepuz PM, Sumoy L, Mas G, et al. (2004) The MAPK Hog1 recruits Rpd3 histone deacetylase to activate osmoresponsive genes. Nature 427: 370-374.

104. Pascual-Ahuir A, Struhl K, Proft M (2006) Genome-wide location analysis of the stress-activated MAP kinase Hog1 in yeast. Methods 40: 272-278.

105. Pokholok DK, Zeitlinger J, Hannett NM, Reynolds DB, Young RA (2006) Activated signal transduction kinases frequently occupy target genes.Science 313: 533-536.

106. Edmunds JW, Mahadevan LC (2006) Cell signaling. Protein kinases seek close encounters with active genes. Science 313: 449-451.

107. Chow CW, Davis RJ (2006) Proteins kinases: chromatin-associated enzymes? Cell 127: 887-890.

108. Proft M, Mas G, de Nadal E, Vendrell A, Noriega N, et al. (2006) The stress-activated Hog1 kinase is a selective transcriptional elongation factor for genes responding to osmotic stress. Mol Cell 23: 241-250.

109. Birbach A, Gold P, Binder BR, Hofer E, de Martin R, et al. (2002) Signaling molecules of the NF-kappa B pathway shuttle constitutively between cytoplasm and nucleus. J Biol Chem 277: 10842-10851.

110. Anest V, Hanson JL, Cogswell PC, Steinbrecher KA, Strahl BD, et al (2003) A nucleosomal function for IkappaB kinase-alpha in NF-kappaBdependent gene expression. Nature 423: 659-663.

111. Yamamoto Y, Verma UN, Prajapati S, Kwak YT, Gaynor RB (2003) Histone $\mathrm{H} 3$ phosphorylation by IKK-alpha is critical for cytokineinduced gene expression. Nature 423: 655-659.

112. Simone C, Forcales SV, Hill DA, Imbalzano AN, Latella L, et al. (2004) p38 pathway targets SWI-SNF chromatin-remodeling complex to muscle-specific loci. Nat Genet 36: 738-743.

113. Metzger E, Imhof A, Patel D, Kahl P, Hoffmeyer K, et al. (2010) Phosphorylation of histone H3T6 by PKCbeta(I) controls demethylation at histone H3K4. Nature 464: 792-796.

114. Li CW, Xia W, Huo L, Lim SO, Wu Y, et al. (2012) Epithelialmesenchymal transition induced by TNF-alpha requires NF-kappaBmediated transcriptional upregulation of Twist1. Cancer Res 72: 1290-1300.

115. Kolosova I, Nethery D, Kern JA (2011) Role of Smad2/3 and p38 MAP kinase in TGF- $\hat{I}^{2} 1$-induced epithelial-mesenchymal transition of pulmonary epithelial cells. J Cell Physiol 226: 1248-1254.

116. Tam WL, Lu H, Buikhuisen J, Soh BS, Lim E, et al. (2013) Protein kinase C $\hat{I} \pm$ is a central signaling node and therapeutic target for breast cancer stem cells. Cancer Cell 24: 347-364.

117. Sideridou M, Zakopoulou R, Evangelou K, Liontos M, Kotsinas A, et al. (2011) Cdc6 expression represses E-cadherin transcription and activates adjacent replication origins. J Cell Biol 195: 1123-1140.

118. Lin T, Ponn A, Hu X, Law BK, Lu J (2010) Requirement of the histone demethylase LSD1 in Snai1-mediated transcriptional repression during epithelial-mesenchymal transition. Oncogene 29: 4896-4904.

119. Cao Q, Yu J, Dhanasekaran SM, Kim JH, Mani RS, et al. (2008) Repression of E-cadherin by the polycomb group protein EZH2 in cancer. Oncogene 27: 7274-7284.

120. Lombaerts M, van Wezel T, Philippo K, Dierssen JW, Zimmerman RM, et al. (2006) E-cadherin transcriptional downregulation by promoter methylation but not mutation is related to epithelial-to-mesenchymal transition in breast cancer cell lines. Br J Cancer 94: 661-671.

121. Peinado H, Ballestar E, Esteller M, Cano A (2004) Snail mediates Ecadherin repression by the recruitment of the Sin3A/histone deacetylase 1 (HDAC1)/HDAC2 complex. Mol Cell Biol 24: 306-319.

122. von Burstin J, Eser S, Paul MC, Seidler B, Brandl M, et al. (2009) Ecadherin regulates metastasis of pancreatic cancer in vivo and is suppressed by a SNAIL/HDAC1/HDAC2 repressor complex. Gastroenterology 137: 361-371, 371.

123. Wang Y, Zhang H, Chen Y, Sun Y, Yang F, et al. (2009) LSD1 is a subunit of the NuRD complex and targets the metastasis programs in breast cancer. Cell 138: 660-672.
124. Sánchez-Tilló E, Lázaro A, Torrent R, Cuatrecasas M, Vaquero EC, et al. (2010) ZEB1 represses E-cadherin and induces an EMT by recruiting the SWI/SNF chromatin-remodeling protein BRG1. Oncogene 29: 3490-3500.

125. Guaita S, Puig I, Franci C, Garrido M, Dominguez D, et al. (2002) Snail induction of epithelial to mesenchymal transition in tumor cells is accompanied by MUC1 repression and ZEB1 expression. J Biol Chem 277: 39209-39216.

126. Yang MH, Hsu DS, Wang HW, Wang HJ, Lan HY, et al. (2010) Bmil is essential in Twist1-induced epithelial-mesenchymal transition. Nat Cell Biol 12: 982-992.

127. Fu J, Qin L, He T, Qin J, Hong J, et al. (2011) The TWIST/Mi2/NuRD protein complex and its essential role in cancer metastasis.Cell Res 21: 275-289.

128. Cheng CW, Wu PE, Yu JC, Huang CS, Yue CT, et al. (2001) Mechanisms of inactivation of E-cadherin in breast carcinoma: modification of the two-hit hypothesis of tumor suppressor gene. Oncogene 20: 3814-3823.

129. Nebbioso A, Carafa V, Benedetti R, Altucci L (2012) Trials with 'epigenetic' drugs: an update. Mol Oncol 6: 657-682.

130. Finzer P, Kuntzen C, Soto U, zur Hausen H, Rosl F (2001) Inhibitors of histone deacetylase arrest cell cycle and induce apoptosis in cervical carcinoma cells circumventing human papillomavirus oncogene expression. Oncogene 20: 4768-4776.

131. Qian DZ, Wang X, Kachhap SK, Kato Y, Wei Y, et al. (2004) The histone deacetylase inhibitor NVP-LAQ824 inhibits angiogenesis and has a greater antitumor effect in combination with the vascular endothelial growth factor receptor tyrosine kinase inhibitor PTK787/ZK222584. Cancer Res 64: 6626-6634.

132. Kwon HJ, Kim MS, Kim MJ, Nakajima H, Kim KW (2002) Histone deacetylase inhibitor FK228 inhibits tumor angiogenesis. Int J Cancer 97: 290-296.

133. Carew JS, Giles FJ, Nawrocki ST (2008) Histone deacetylase inhibitors: mechanisms of cell death and promise in combination cancer therapy. Cancer Lett 269: 7-17.

134. Kanwal R, Gupta S (2010) Epigenetics and cancer. J Appl Physiol (1985) 109: 598-605.

135. Duvic M, Talpur R, Ni X, Zhang C, Hazarika P, et al. (2007) Phase 2 trial of oral vorinostat (suberoylanilide hydroxamic acid, SAHA) for refractory cutaneous T-cell lymphoma (CTCL).Blood 109: 31-39.

136. Olsen EA, Kim YH, Kuzel TM, Pacheco TR, Foss FM, et al. (2007) Phase IIb multicenter trial of vorinostat in patients with persistent, progressive, or treatment refractory cutaneous T-cell lymphoma. J Clin Oncol 25: 3109-3115.

137. Ramaswamy B, Fiskus W, Cohen B, Pellegrino C, Hershman DL, et al. (2012) Phase I-II study of vorinostat plus paclitaxel and bevacizumab in metastatic breast cancer: evidence for vorinostat-induced tubulin acetylation and Hsp90 inhibition in vivo. Breast Cancer Res Treat 132: 1063-1072.

138. Dimopoulos M, Siegel DS, Lonial S, Qi J, Hajek R, et al. (2013) Vorinostat or placebo in combination with bortezomib in patients with multiple myeloma (VANTAGE 088): a multicentre, randomised, double-blind study. Lancet Oncol 14: 1129-1140.

139. Richardson PG, Schlossman RL, Alsina M, Weber DM, Coutre SE, et al (2013) PANORAMA 2: panobinostat in combination with bortezomib and dexamethasone in patients with relapsed and bortezomib-refractory myeloma. Blood 122: 2331-2337.

140. Mackay HJ, Hirte H, Colgan T, Covens A, MacAlpine K, et al. (2010) Phase II trial of the histone deacetylase inhibitor belinostat in women with platinum resistant epithelial ovarian cancer and micropapillary (LMP) ovarian tumours. Eur J Cancer 46: 1573-1579.

141. Lakshmaiah KC, Jacob LA, Aparna S, Lokanatha D, Saldanha SC (2014) Epigenetic therapy of cancer with histone deacetylase inhibitors. J Cancer Res Ther 10: 469-478.

142. Yoshiura K, Kanai Y, Ochiai A, Shimoyama Y, Sugimura T, et al. (1995) Silencing of the E-cadherin invasion-suppressor gene by $\mathrm{CpG}$ 
Citation: Boulding T, Wu F, Zafar A, Rao S (2015) Multi-Layered Epigenetic Regulatory Mechanisms Mediate Epithelial to Mesenchymal Transition in Cancer. J Integr Oncol 4: 127. doi:10.4172/2167-0897.1000127

Page 9 of 9

methylation in human carcinomas. Proc Natl Acad Sci U S A 92: 7416-7419.

143. Corn PG, Smith BD, Ruckdeschel ES, Douglas D, Baylin SB, et al. (2000) E-cadherin expression is silenced by 5 ' $\mathrm{CpG}$ island methylation in acute leukemia. Clin Cancer Res 6: 4243-4248.

144. Nam JS, Ino Y, Kanai Y, Sakamoto M, Hirohashi S (2004) 5-aza-2'deoxycytidine restores the E-cadherin system in E-cadherin-silenced cancer cells and reduces cancer metastasis. Clin Exp Metastasis 21: 49-56.

145. Barshishat M, Polak-Charcon S, Schwartz B (2000) Butyrate regulates Ecadherin transcription, isoform expression and intracellular position in colon cancer cells. Br J Cancer 82: 195-203.

146. Takai N, Desmond JC, Kumagai T, Gui D, Said JW, et al. (2004) Histone deacetylase inhibitors have a profound antigrowth activity in endometrial cancer cells. Clin Cancer Res 10: 1141-1149.

147. Masuda T, Saito H, Kaneko F, Atsukawa K, Morita M, et al. (2000) Upregulation of E-cadherin and I-catenin in human hepatocellular carcinoma cell lines by sodium butyrate and interferon-alpha. In Vitro Cell Dev Biol Anim 36: 387-394.

148. Shah P, Gau Y, Sabnis G (2014) Histone deacetylase inhibitor entinostat reverses epithelial to mesenchymal transition of breast cancer cells by reversing the repression of E-cadherin. Breast Cancer Res Treat 143: 99-111.

149. Kong D, Ahmad A, Bao B, Li Y, Banerjee S, et al. (2012) Histone deacetylase inhibitors induce epithelial-to-mesenchymal transition in prostate cancer cells. PLoS One 7: e45045.

150. Giudice FS, Pinto DS Jr, Nör JE, Squarize CH, Castilho RM (2013) Inhibition of histone deacetylase impacts cancer stem cells and induces epithelial-mesenchyme transition of head and neck cancer. PLoS One 8: e58672.

151. Uchida H, Maruyama T, Nishikawa-Uchida S, Oda H, Miyazaki K, et al. (2012) Studies using an in vitro model show evidence of involvement of epithelial-mesenchymal transition of human endometrial epithelial cells in human embryo implantation. J Biol Chem 287: 4441-4450.

152. Benmaamar R (2014) Epigenetic modification boosts ovarian cancer vaccination. Lancet Oncol 15: e55.

153. Zhang J, Chen YL, Ji G, Fang W, Gao Z, et al. (2013) Sorafenib inhibits epithelial-mesenchymal transition through an epigenetic-based mechanism in human lung epithelial cells. PLoS One 8: e64954.

154. Mani SA, Guo W, Liao MJ, Eaton EN, Ayyanan A, et al. (2008) The epithelial-mesenchymal transition generates cells with properties of stem cells. Cell 133: 704-715.

155. Wang J, Lu F, Ren Q, Sun H, Xu Z, et al. (2011) Novel histone demethylase LSD1 inhibitors selectively target cancer cells with pluripotent stem cell properties. Cancer Res 71: 7238-7249.

156. Kyuno D, Kojima T, Yamaguchi H, Ito T, Kimura Y, et al. (2013) Protein kinase Calpha inhibitor protects against downregulation of claudin-1 during epithelial-mesenchymal transition of pancreatic cancer. Carcinogenesis 34: 1232-1243.

157. Chen Z, Forman LW, Williams RM, Faller DV (2014) Protein kinase C-Î' inactivation inhibits the proliferation and survival of cancer stem cells in culture and in vivo. BMC Cancer 14: 90.

158. Regala RP, Davis RK, Kunz A, Khoor A, Leitges M, et al. (2009) Atypical protein kinase $\mathrm{C}\{$ iota $\}$ is required for bronchioalveolar stem cell expansion and lung tumorigenesis. Cancer Res 69: 7603-7611. 